\title{
Designing and Evaluating Bamboo Harvesting Methods for Local Needs: Integrating Local Ecological Knowledge and Science
}

\author{
András Darabant ${ }^{1}$ - Prem Bahadur Rai ${ }^{2}$ Christina Lynn Staudhammer ${ }^{3}$. \\ Tshewang Dorji ${ }^{2}$
}

Received: 13 October 2015/Accepted: 15 April 2016/Published online: 25 April 2016

(c) The Author(s) 2016. This article is published with open access at Springerlink.com

\begin{abstract}
Dendrocalamus hamiltonii, a large, clumpforming bamboo, has great potential to contribute towards poverty alleviation efforts across its distributional range. Harvesting methods that maximize yield while they fulfill local objectives and ensure sustainability are a research priority. Documenting local ecological knowledge on the species and identifying local users' goals for its production, we defined three harvesting treatments (selective cut, horseshoe cut, clear cut) and experimentally compared them with a no-intervention control treatment in an action research framework. We implemented harvesting over three seasons and monitored annually and two years posttreatment. Even though the total number of culms positively influenced the number of shoots regenerated, a much stronger relationship was detected between the number of culms harvested and the number of shoots regenerated, indicating compensatory growth mechanisms to guide shoot regeneration. Shoot recruitment declined over time in all treatments as well as the control; however, there was no difference among harvest treatments. Culm recruitment declined with an increase in harvesting intensity. When univariately assessing the number of harvested culms and shoots, there were no differences among treatments. However, multivariate analyses simultaneously
\end{abstract}

András Darabant

darabant@gmail.com

1 Department of Forest and Soil Sciences, University of Natural Resources and Life Sciences, Peter Jordan Strasse 82, 1190 Vienna, Austria

2 Ugyen Wangchuk Institute for Conservation and Environmental Research, Lamai Goempa, Bumthang, Bhutan

3 Department of Biological Sciences, University of Alabama, Box 870344, Tuscaloosa, AL 35487, USA considering both variables showed that harvested output of shoots and culms was higher with clear cut and horseshoe cut as compared to selective cut. Given the ease of implementation and issues of work safety, users preferred the horseshoe cut, but the lack of sustainability of shoot production calls for investigating longer cutting cycles.

Keywords Dendrocalamus hamiltonii $\cdot$ Bamboo silviculture · NTFP harvesting · Local ecological knowledge $\cdot$ Participatory action research

\section{Introduction}

Globally, more than 1.6 billion people depend on forests for their livelihoods to some degree (Angelsen and Wunder 2003), and this dependence is stronger in remote places with high levels of poverty (Sunderlin et al. 2008). In these areas, non-timber forest products (NTFPs) frequently play an important "safety-net" function for rural poor (Belcher and Schreckenberg 2007) and thus reduce risk. Moreover, the rate of return for NTFPs typically exceeds that generated by agricultural activities (Krishnankutty 2004; Pandit and Kumar 2010). Beyond subsistence, forest products also provide employment and income opportunities for local forest users (Arnold and Pérez 2001). Commercialization of NTFPs has been promoted for environmental conservation and livelihood support but often has failed to achieve these outcomes simultaneously (Arnold and Pérez 2001; Kusters et al. 2006). While marketing and sales are apparently the most important constraints (Marshall et al. 2003), the lack of sustainable utilization methods remains a key challenge to successful NTFP development (Belcher and Schreckenberg 2007; Wong et al. 2001). Initially successful NTFP-based cottage industries are frequently 
affected by declines in production resulting from overharvesting or improper management of the resource base due to lack of appropriate management guidelines (Prommegger et al. 2005; Moktan et al. 2009).

Scientific knowledge on NTFPs is frequently limited as a result of the relatively recent public interest in these commodities and their great diversity. At the same time, community-based management relying on local ecological knowledge (LEK) has yielded positive outcomes in managing NTFPs (Rist et al. 2010). LEK, however, varies widely within user groups (Chalmers and Fabricius 2007) and may be limited to selected aspects of the ecology, growth conditions, and utilization of particular species and ecosystems (Ballard and Huntsinger 2006; Nath et al. 2015a). LEK on NTFPs that are traditionally harvested for subsistence is frequently limited to experiences with extensive, low intensity utilization. Improved marketing, sales, and transport opportunities open possibilities for commercialization of NTFPs (Marshall et al. 2003) and may lead to a change of the household strategy in managing NTFPs, from subsistence to supplementary or integrated management (Belcher et al. 2005). This shift of the household strategy inevitably results in higher intensity management, for which traditional resource management approaches may not be adequate, leading to over-harvesting and resource decline (Belcher and Schreckenberg 2007). In such situations, LEK may not provide adequate answers to complex, knowledge intensive practices, particularly if these have emerged recently (Ingram 2008). Co-production of knowledge between scientists and users may provide answers in such situations (Kainer et al. 2009; Kristjanson et al. 2009). Moreover, the scientific testing of LEK provides a possible way to integrate it into formal management plans (Ticktin and Johns 2002), which are often required by governments for recognizing traditional rights and community-based management (Leach et al. 1999). Harvesting regimes of NTFPs must maximize sustainable output of the target commodity, but they also need to fit the local socio-economic context. Participatory action research provides a useful framework to develop and test harvesting regimes integrating LEK and provides a platform for disseminating findings into practice (Ticktin et al. 2002).

Bamboos are versatile and weakly perishable non-timber forest products that are important sources of livelihood in many rural areas (Lobovikov et al. 2012). Throughout monsoonal Asia, bamboo culms are widely used for construction, fencing, and handicrafts, while bamboo shoots are an important dietary supplement of high nutritional value (Bhatt et al. 2005; Moktan et al. 2009). Additionally, the carbon sequestration potential of bamboo groves can further increase their livelihood contribution (Nath et al. 2015b). Bamboo-based local enterprises have successfully contributed to poverty alleviation (Zhu 2003; Moktan et al.
2009) and have large economic potential in the region (Bhatt et al. 2003). Accordingly, bamboo production within the legal framework of community forests also formed part of national development targets for community-based natural resource management in Bhutan (Gross National Happiness Commission 2008). Based on their abundance, easy propagation, multi-purpose use, and economic potential, Dendrocalamus spp. have been identified as one of the three bamboo taxa for NTFP development in the country (Social Forestry Division 2008). Shoots and culms are mainly used for domestic purposes at present, while commercial markets for most species and products are weakly developed.

Bamboo shoot production mainly depends on the harvesting regime (thinning of culms), as well as on water and nutrient supply (Kleinhenz and Midmore 2001). The only reasonably applicable bamboo management intervention in Bhutan is culm thinning, since irrigation, fertilizing, and mulching are highly labor and cost intensive, and their application would divert resources away from agricultural production. However, systematic clump management regimes are essential to prevent random harvesting, which results in a decline of clump productivity (Virtucio 2009). Harvesting regimes relevant in our context have been developed for D. strictus in India (Tewari 1992), as well as D. asper (Decipulo et al. 2009) and Bambusa blumeana (Marquez 2009; Malab et al. 2009) in the Philippines, with the aim of maintaining balanced age distributions of young (1- to 3-yearold) culms. Harvesting promotes clump regeneration: bamboo genets compensate for the loss of photosynthetically active tissue by mobilizing reserves from belowground rhizomes and allocating them to the production of new shoots. The majority of young shoots regenerate on rhizomes belonging to one- to two-year-old culms. Therefore, harvesting of these culms detrimentally affects regeneration (Malab et al. 2009), a trade-off which must be considered for bamboo shoot and culm production objectives.

In order to address the most important questions of community-based sustainable utilization of $D$. hamiltonii Munro var. edulis Munro, the most important bamboo species in southern Bhutan, the objectives of the present study were to (1) describe the state of local ecological knowledge (LEK) about D. hamiltonii Munro var. edulis Munro, and (2) test and evaluate harvesting methods designed by integrating LEK and science.

\section{Materials and Methods}

\section{Species and Study Area}

D. hamiltonii is a large sympodial bamboo with pachymorph rhizomes and culms, which grow up to 25 meters 
height (Stapleton 2000). The distribution of D. hamiltonii Munro (common name: Pakshing) ranges from the central Himalayas to northeast India (Troup 1921; Seethalakshmi and Kumar 1998), and includes the subtropical and warmtemperate broadleaf zones of Bhutan up to an altitude of $1800 \mathrm{~m}$ (Stapleton 2000). D. hamiltonii Munro var. edulis Munro is especially palatable with high nutritional value (Bhatt et al. 2005) and is common in central and eastern Bhutan (Stapleton et al. 1997). It occurs in open forests, frequently establishing after disturbances (Seethalakshmi and Kumar 1998) and is often cultivated. Thin-walled culms lead to flexibility, making it suitable as an all-purpose weaving material. Although thin walled, culms are also preferred as fencing material over other bamboo species because of their roughness and durability (Rai pers. comm.). The foliage is harvested to feed cattle and horses and is grazed by mithun (Bos frontalis) (Sundriyal and Sundriyal 2004). Shoots start to appear at the beginning of June, are harvested between mid-June and the end of August, and are consumed fresh, dried, shredded, or pickled.

The research site was located west of Tshanglajong village $\left(27^{\circ} 06^{\prime} 27.54^{\prime \prime} \mathrm{N}, 90^{\circ} 42^{\prime} 26.77^{\prime \prime} \mathrm{E}\right)$ on an east-northeast facing slope at $870 \mathrm{~m}$ altitude with moderately moist site conditions. The village is located in Zhemgang district along the lower Mangduechu valley at an altitude ranging from 700 to $1000 \mathrm{~m}$. Mean annual minimum and maximum temperatures measured at the Yebilaptsha climate station $2.6 \mathrm{~km}$ away are 15.2 and $26.2{ }^{\circ} \mathrm{C}$, respectively. The mean annual precipitation is $1750 \mathrm{~mm}$, the bulk of which falls during the summer monsoon period from May to September. The village was settled approx. 95 years ago, which is why we decided to use the term LEK instead of traditional ecological knowledge. The surrounding area is dominated by open D. hamiltonii forests (Rao and Saxena 1995). A community forest partially focusing on management of $D$. hamiltonii was incorporated in Tshanglajong a year after the start of the present study.

\section{Survey of Local Ecological Knowledge on Bamboo Ecology and Use}

In an action research framework, social research methods were applied to gain insight into LEK on bamboo ecology, harvesting methods, utilization, socio-economic significance, and farmer's objectives regarding bamboo use. Specific methods applied included semi-directive interviews, an analytical workshop and collaborative field work (Huntington 2000). All researchers in the field spoke the local language.

Semi-directive interviews were conducted to identify general patterns of LEK and local objectives of bamboo utilization. Invitations to attend a structured analytical workshop to triangulate interview findings and to define bamboo management objectives were sent to all households, and as habitual in Bhutan, one representative per household with the widest experience on the topic attended. Documentation of LEK focused on distribution, habitat characteristics, phenology, growth characteristics, age determination, morphology, yield, traditional harvesting techniques, utilization, income generation, and related employment, as well as legal and regulatory constraints related to bamboos and their utilization. Documented LEK was used to facilitate the identification of people's goals regarding bamboo utilization and to design experimental treatments for bamboo harvesting focusing on these goals. Collaborative field work was conducted in the forest and helped verify the information obtained during the analytical workshop and gain practical insight into the subject. The approach also facilitated the development of ownership over the research and its results by users.

\section{Experimental Harvesting Methods and Data Collection}

Experimental treatments were designed based on the requirements of local users in terms of labor input, its timing and the output of desired products. The experiment was established in spring 2009 with random selection of 16 bamboo clumps located in an area of approximately 0.25 ha to ensure homogenous environmental conditions. Selected bamboo clumps had no damage or signs of harvesting and had clearly defined clump edges. Treatments were defined by a combination of harvesting prescriptions for shoots and culms (Table 1) and applied randomly to selected clumps after initial measurements. The 16 bamboo clumps were evenly allocated to treatments and controls, such that four clumps received each of the three harvest treatments, and four clumps were reserved as controls.

The three harvest treatments increased in intensity: selective cut, horseshoe cut, and clear cut. Selective cut was defined by low intensity removal of shoots and culms ( $25 \%$ each). Since destruction of shoots near the perimeter of clumps may lead to clump congestion and ultimately to degradation (Troup 1921; Franklin 2008), selective harvest of culms started in clump centers. The horseshoe method is widely practiced in India and Nepal, and was applied orienting the convex arch of the shoe facing uphill in order to prevent accumulation of debris in the arch. With this method, new shoots are mainly added on the outer arch of the horseshoe, and therefore clumps are expected to expand uphill (Bradshaw 1997). Both shoots and culms were harvested at $75 \%$ intensity with the horseshoe method. The clear cut treatment included the removal of $50 \%$ of new shoots and all culms older than two years (Table 1). Culms 
Table 1 Harvest treatments applied to clumps of Dendrocalamus hamiltonii

\begin{tabular}{llcl}
\hline Treatment & $\begin{array}{l}\text { Shoots } \\
\text { harvested }(\%)\end{array}$ & $\begin{array}{l}\text { Culms }>2 \text { years } \\
\text { harvested }(\%)\end{array}$ & Description \\
\hline Control & 0 & 0 & $\begin{array}{l}\text { No intervention } \\
\text { Removal of dead culms and stumps, harvest of } \\
\text { shoots and culms from inside out } \\
\text { Selective cut }\end{array}$ \\
Horseshoe cut & 75 & 25 & $\begin{array}{l}\text { Removal of dead culms and stumps, convex } \\
\text { arch facing upslope, harvest of shoots and } \\
\text { culms from inside of arch } \\
\text { Removal of dead culms and stumps, harvest of } \\
\text { shoots from inside out }\end{array}$ \\
\hline
\end{tabular}

were harvested above the second node, resulting in a minimal stump height of approx. 10-25 cm.

Monitoring and harvesting were carried out in seasons corresponding to roughly defined traditional harvesting seasons (summer for shoots, winter for culms). Monitoring consisted of enumeration of harvestable shoots and culms. Shoots and culms of no value to local users (dead, broken, undersized, not of the right age) were excluded from enumeration. Harvesting of culms was restricted to culms older than two years, as younger culms are of limited use, and because buds on their rhizomes form new shoots. Because the recruitment of Dendrocalamus varies greatly between years (Decipulo et al. 2009; Marquez 2009), harvesting and monitoring took place in 2009, 2010, and 2011. Additionally, culm dynamics were monitored until 2013, by enumerating shoot and culm recruitment. For each clump, we measured initial clump diameter, enumerated initial number of present-year and older live and dead culms, as well as the number of annually harvested shoots and culms.

\section{Data Analysis}

Audio results of participatory exercises were not recorded, since this is not customary in Bhutan. Instead, the interviews were noted and compiled manually. Results were presented and verified in the analytical workshop, which was additionally used to reach a consensus on participants' objectives regarding bamboo utilization.

For all experimental data, we initially computed descriptive statistics and the Pearson correlation coefficient for all pairs of variables. We then performed two preliminary linear regression analyses to illuminate the relationship between shoot recruitment in 2010 and (1) the total number of culms in 2009, and (2) the number of culms harvested in 2009. General linear mixed models (GLMMs) were then formulated to evaluate the effects of harvest treatments on the bamboo resource over the study period. We estimated models to quantify the effect of harvesting on (3) clump diameter, (4) productivity index (PI), defined as the ratio of shoot recruitment to the number of culms per clump (following Midmore 2009), (5) harvesting response, defined as the ratio of shoot recruitment to the number of harvested culms per clump, (6) shoot recruitment, (7) culm recruitment, (8) shoots harvested, and (9) culms harvested. GLMMs were formulated to include fixed effects for treatment, year as a repeated effect, and their interaction. In addition, to account for the potential influence of initial values, the analysis of clump diameter (3) included initial diameter (in 2009) as a covariate. The productivity analysis (4) included the current-year culm production as a covariate. The analyses for shoot and culm recruitment (6 and 7) and harvest (8 and 9) included the cumulative harvest as a covariate. Because data from the same clump are likely more correlated than those from different clumps, these GLMMs included a random effect for clumps with a compound symmetric error structure to account for the correlation among shoots in the same clump. A KenwardRoger approximation was used to adjust the degrees of freedom as suggested for mixed models (Kenward and Roger 1997). To meet the assumptions of normality and homoscedasticity, a square root transformation was performed for harvesting response, culm recruitment, and culms harvested. A log-transformation was performed for PI. All analyses involving harvesting data (harvesting response, shoots harvested, and culms harvested) were performed on treated data only (i.e., all control data were excluded, since no harvest occurred).

Shoot and culm harvest were identified to be equal management priorities (see Results). Thus, we also analyzed harvest data pooled over three years in order to evaluate differences in shoot and culm harvest over the entire period simultaneously (analysis 10). This resulted in dependent variables for combined shoot harvest (2010 and 2011), and combined culm harvest (2009, 2010, and 2011), which could be analyzed in a fixed-effects ANOVA framework. Since the simultaneous assessment of numbers of shoots and of culms represents a multivariate question involving the interaction and trade-off between two response variables, we performed a multivariate ANOVA (MANOVA; 10) rather than separate univariate ANOVAs 
(Scheiner 2001). As the control treatment did not include harvest by definition, data from these clumps were excluded from the analysis. As in the univariate analyses, the initial clump diameter and the initial number of culms in 2009 were included as covariates in analyses as proxies for initial clump size, resulting in a multivariate analysis of covariance (MANCOVA).

Since appropriate interpretation of GLMMs, MANCOVA, and ANOVA results requires normality and homoscedasticity of residuals, these were verified by visual examination of residual graphs. Where significant differences by treatment were indicated $(p \leq 0.05)$, a Scheffé test was performed on univariate estimated marginal means. Where appropriate, marginal means were backtransformed, taking into account bias introduced by logtransformation (sensu Sprugel 1983). Where a significant treatment by year interaction was detected, the simple effect of treatment within each year was tested via tests of simple effects (Winer 1971). Multivariate differences in response variables were evaluated via Wilks' $\lambda$, which is a multivariate $\mathrm{F}$ test of the ratio of the variance/covariance matrices of the errors versus the effects. However, because these means are not adjusted for the correlation between dependent variables in the MANCOVA, we then performed multivariate comparisons among treatments via orthogonal contrasts. All analyses were conducted using SAS (version 9.2) via procedures PROC REG, PROC MIXED, and PROC GLM (SAS Institute Inc. 2002-2008).

\section{Results}

\section{Local Ecological Knowledge and Local Users' Objectives}

Of the six species of bamboos growing in and around Tshanglajong, local users reported that D. hamiltonii was the only species used for a wide variety of purposes, such as fencing, weaving, and construction. Local users observed that $D$. hamiltonii grows best in valleys and depressions and in general under open forest canopy. They had encountered sporadic, but no mass flowering of $D$. hamiltonii, followed by monocarpic die-off of clumps. Local users did not apply specific methods of harvesting, nor did they apply local restrictions on collection time; rather, they harvested shoots and culms whenever available or required. Stump height was determined by ease of cut and was usually higher towards clump centers and in highly congested clumps. Easily accessible culms of suitable quality, usually near to clump edges, were reportedly harvested on a preferential basis. Collection time for shoots, of which the top $30-40 \mathrm{~cm}$ are harvested, was determined by their emergence, generally in July and
August. Harvesting of culms was mostly done during the dry winter season to prevent borer damage.

The assignment of culms to different uses depended on physical qualities, which are a function of culm age. Users were confident to determine culm age up to three years based on morphological properties. Young culms were used for weaving, while older ones were used for construction purposes. Products were either sold locally, in the nearest town at eight $\mathrm{km}$ distance, or the district headquarters at $42 \mathrm{~km}$ distance. Bamboo culms were sold infrequently. Parts of the population reported occasionally engaging in weaving of mats and baskets for domestic as well as commercial purposes. In spite of its abundance, however, only two local users were intensively involved in bamboo harvesting and processing. People were interested in harvesting both shoots and culms, but did not want to devote much time and resources towards bamboo activities due to unreliable markets.

\section{Bamboo Clump Properties}

The relationship between the number of culms in 2009 and the number of shoots regenerated per clump in 2010 was weak ( $r^{2}=0.14$, Fig. 1$)$. On the other hand, the relationship between the number of culms harvested per clump in 2009 and the number of shoots regenerated in 2010 was stronger and significant $\left(r^{2}=0.46\right.$, Fig. 2).

Prior to application of treatments in 2009, mean clump diameter was $308 \mathrm{~cm}$, and on average a clump had 21 culms with a median culm diameter of $8.56 \mathrm{~cm}$ (Table 2). About $15 \%$ of culms were dead, while $13 \%$ were currentyear culms. Over the course of the experiment, neither time nor harvesting treatments nor their interaction showed

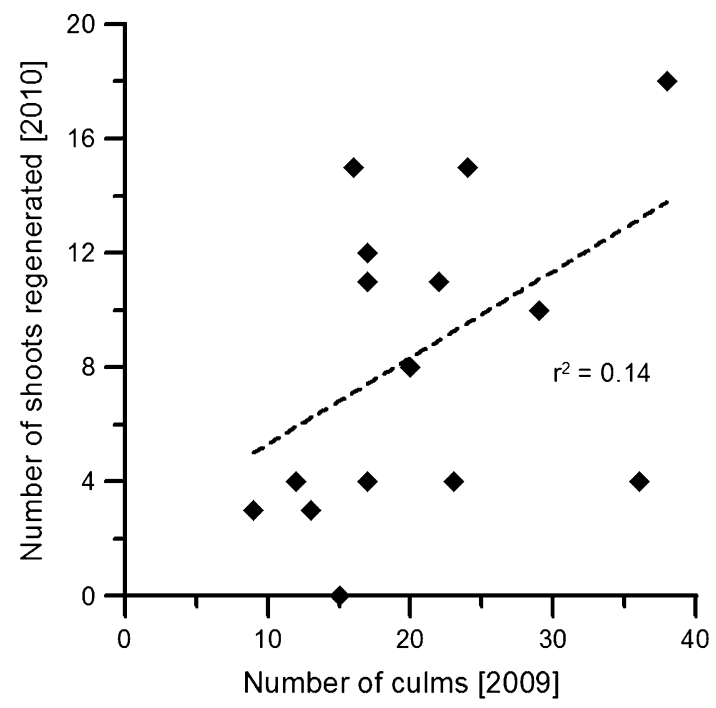

Fig. 1 Relationship between number of culms per clump and number of shoots emerged the following summer 


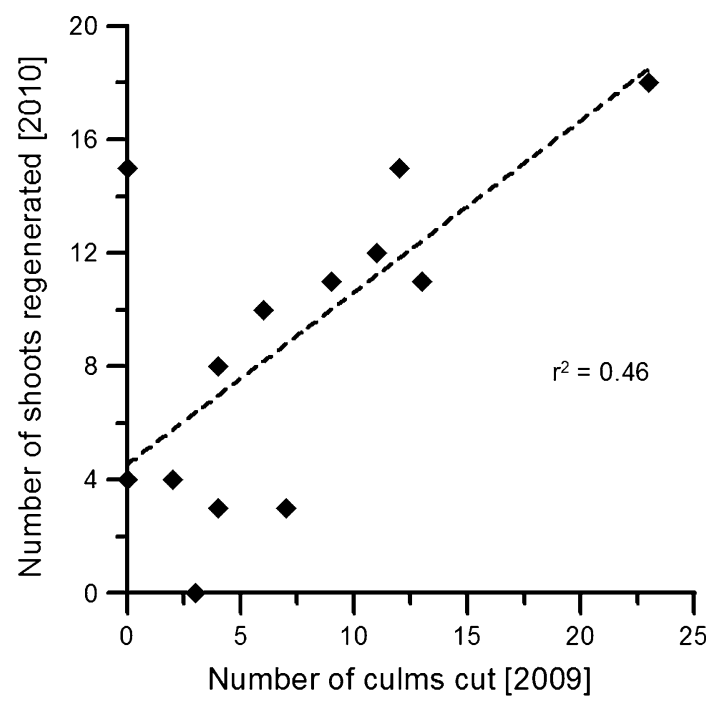

Fig. 2 Relationship between number of culms harvested per clump and number of shoots emerged the following summer

Table 2 Bamboo clump characteristics prior to application of treatments in 2009

\begin{tabular}{lcc}
\hline Parameter & Mean & Standard error \\
\hline Clump diameter $(\mathrm{cm})$ & 308.44 & 74.68 \\
Total number of culms & 20.75 & 8.16 \\
Median culm diameter $(\mathrm{cm})$ & 8.56 & 0.89 \\
Proportion of current-year culms & 0.126 & 0.107 \\
Proportion of dead culms & 0.151 & 0.105 \\
\hline
\end{tabular}

significant effects on clump diameter (Table 3, Analysis 3, $p>0.05)$.

\section{Productivity Index and Harvesting Response Under Experimental Treatments}

We observed significantly different Productivity Indices among treatments by year (Table 3 , Analysis $4, p \leq 0.05$ ). Tests of simple effects showed that in 2010 the control treatment had a significantly lower proportion of shoots, as compared to harvest treatments. Clear cut and horseshoe cut treatments also differed significantly from each other in the same year. PI showed a significant decline over time irrespective of the type of harvest, but this decline was not observed in the control treatment. From 2011 onwards, there was no significant difference among treatments ( $p \leq 0.05$; Fig. 3).

The harvesting response also differed significantly among treatments by year (Table 3 , Analysis $5, p \leq 0.05$ ). Harvesting response was significantly higher with selective cut as compared to horseshoe cut in 2011 and with clearcut as compared to selective cut in 2013 ( $p \leq 0.05$; Fig. 4). In the first year after harvest, all treatments led to greater recruitment of new shoots as compared to the number of culms harvested in the previous year. By the end of the observation period, this ratio fell below the level of potential self-replacement with all treatments (Fig. 4).

\section{Recruitment and Harvest of Shoots and Culms Under Experimental Treatments}

While recruitment and harvest of shoots constantly declined over time irrespective of treatments, these negative trends were less consistent and showed fluctuations in the case of culms. Recruitment generally decreased with the intensity of treatments and harvested output did not differ among treatments (Fig. 5).

There was a significant time $\mathrm{x}$ treatment interaction for shoot recruitment (Table 3, Analysis $6, p \leq 0.05$ ). A test of simple effects confirmed differences in shoot recruitment between control and the rest of the treatments in 2011 and 2013 ( $p \leq 0.05$ ). Declining shoot recruitment was confirmed by significant differences among years for all treatments but control (Fig. 5a). Similarly, there was a significant time $\mathrm{x}$ treatment interaction on culm recruitment (Table 3, Analysis $7, p \leq 0.01$ ), and tests of simple effects confirmed increasingly diverging mean culm numbers between treatments. The culm population of the control treatment was significantly higher than of other treatments from 2010 onwards. Additionally, the culm population of selective cut was significantly higher than of clearcut in 2013 ( $p \leq 0.05$; Fig. 5b). Time but not harvest treatment had a significant effect on the number of shoots harvested (Table 3, Analysis $8, p \leq 0.01$ ), which showed a significant decline from 2010 to 2011 ( $p \leq 0.05$; Fig. 5c). Similarly, only time showed a significant effect on the number of harvested culms (Table 3, Analysis 9, $p \leq 0.001$ ). From 2009 to 2010 culm harvest showed a significant decline and from 2010 to 2011 and significant increase ( $p \leq 0.05$; Fig. 5d).

The multivariate test of differences among harvest treatments was statistically significant (Analysis 10, Wilk's $\lambda=0.128, p \leq 0.01$ ), and the model explained a large proportion of the variation of the response variables. The number of culms before application of treatments was a significant covariate in the multivariate model (Wilk's $\lambda=0.173$, $p \leq 0.01)$ and was significant in both separate univariate GLMMs (Table 4). The number of shoots and culms harvested was significantly lower with selective cut as compared to the other two treatments (Fig. 6; contrasts, $p \leq 0.05$ ).

\section{Practical Experiences with Experimental Harvesting}

Users considered clear cut most easy to apply, but the lack of sustainability of this method was imminent to them. The initial implementation of the horseshoe harvest required the 
Table 3 GLMM Type III test of fixed effects of various Dendrocalamus hamiltonii response variables to experimental harvest treatments, year, and initial conditions

\begin{tabular}{|c|c|c|c|c|c|}
\hline Response variable & Source & Num DF & Den DF & $f$ value & $\operatorname{Pr}>F$ \\
\hline \multirow[t]{4}{*}{ 3) Clump diameter } & Treatment & 3 & 11 & 2.99 & 0.0775 \\
\hline & Year & 2 & 24 & 0.59 & 0.5615 \\
\hline & Treatment*year & 6 & 24 & 1.90 & 0.1228 \\
\hline & Initial clump diameter & 1 & 11 & 12.11 & 0.0051 \\
\hline \multirow[t]{3}{*}{ 4) Productivity index } & Treatment & 3 & 12.3 & 3.81 & 0.0389 \\
\hline & Year & 2 & 23.8 & 26.05 & $<0.0001$ \\
\hline & Treatment*year & 6 & 23.7 & 2.55 & 0.0473 \\
\hline \multirow[t]{4}{*}{ 5) Harvesting response } & Treatment & 2 & 8.39 & 3.03 & 0.1024 \\
\hline & Year & 2 & 17.8 & 10.19 & 0.0011 \\
\hline & Treatment*year & 4 & 15.5 & 3.68 & 0.0271 \\
\hline & Current culm production & 1 & 16.9 & 12.13 & 0.0029 \\
\hline \multirow[t]{4}{*}{ 6) Shoot recruitment } & Treatment & 3 & 11.7 & 4.71 & 0.0222 \\
\hline & Year & 2 & 28.6 & 25.46 & $<0.0001$ \\
\hline & Treatment*year & 6 & 24.6 & 2.89 & 0.0283 \\
\hline & Cumulated harvest & 1 & 14.6 & 25.41 & 0.0002 \\
\hline \multirow[t]{4}{*}{ 7) Culm recruitment } & Treatment & 3 & 10.1 & 8.95 & 0.0034 \\
\hline & Year & 3 & 36.5 & 36.16 & $<0.0001$ \\
\hline & Treatment*year & 9 & 32.7 & 3.77 & 0.0024 \\
\hline & Cumulated harvest & 1 & 45.3 & 3.85 & 0.0559 \\
\hline \multirow[t]{4}{*}{ 8) Shoot harvest } & Treatment & 2 & 8.02 & 2.36 & 0.1561 \\
\hline & Year & 1 & 9.33 & 14.64 & 0.0038 \\
\hline & Treatment*year & 2 & 9.11 & 4.01 & 0.0563 \\
\hline & Cumulated harvest & 1 & 8.08 & 61.41 & $<0.0001$ \\
\hline \multirow[t]{4}{*}{ 9) Culm harvest } & Treatment & 2 & 2.66 & 2.56 & 0.2405 \\
\hline & Year & 2 & 11.7 & 16.59 & 0.0004 \\
\hline & Treatment*year & 4 & 7.98 & 2.93 & 0.0914 \\
\hline & Cumulated harvest & 1 & 25 & 0.09 & 0.7623 \\
\hline
\end{tabular}

Bold values indicate significant interactive effects, or in their absence significant individual effects

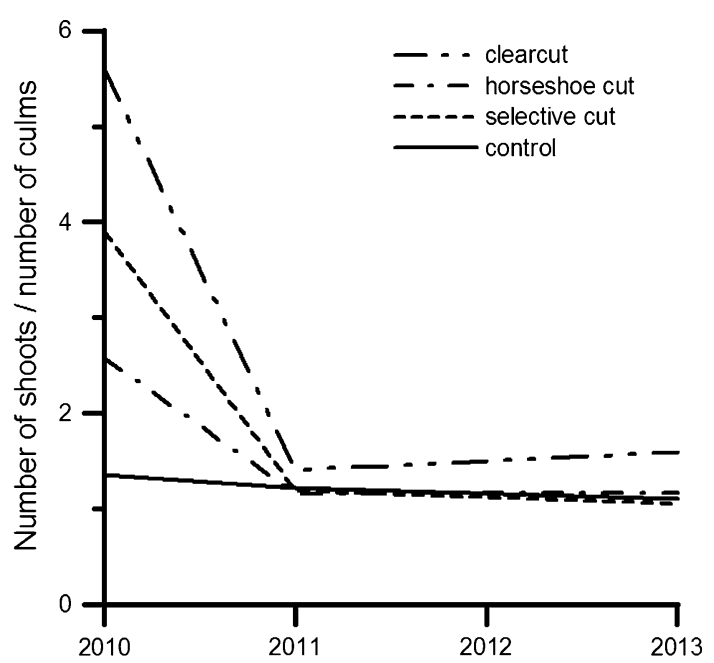

Fig. 3 Productivity index under three harvest and control treatments

greatest effort in terms of labor input. Difficult situations arose when interlocking bamboo culms under tension had to be cut and carefully extracted from among the culms,

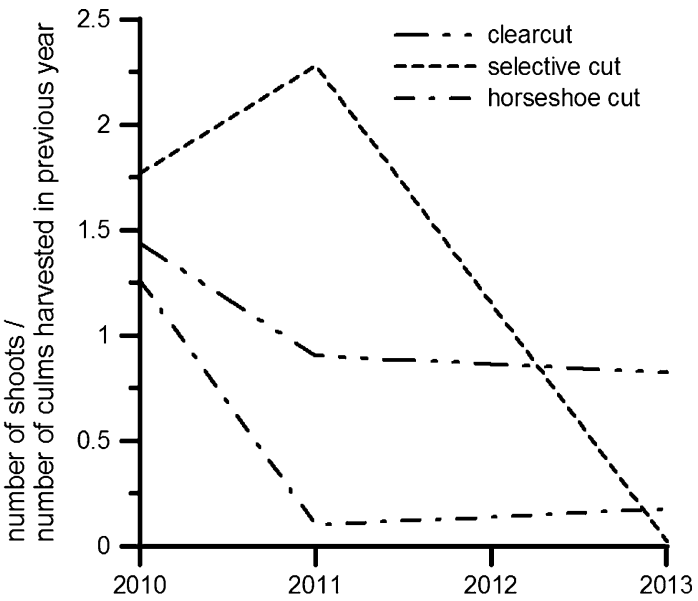

Fig. 4 Harvesting response over time under three harvest treatments

which were retained. Subsequently, the horseshoe method proved easier to administer, as culms and shoots were readily accessible for harvesting from clump edges. 


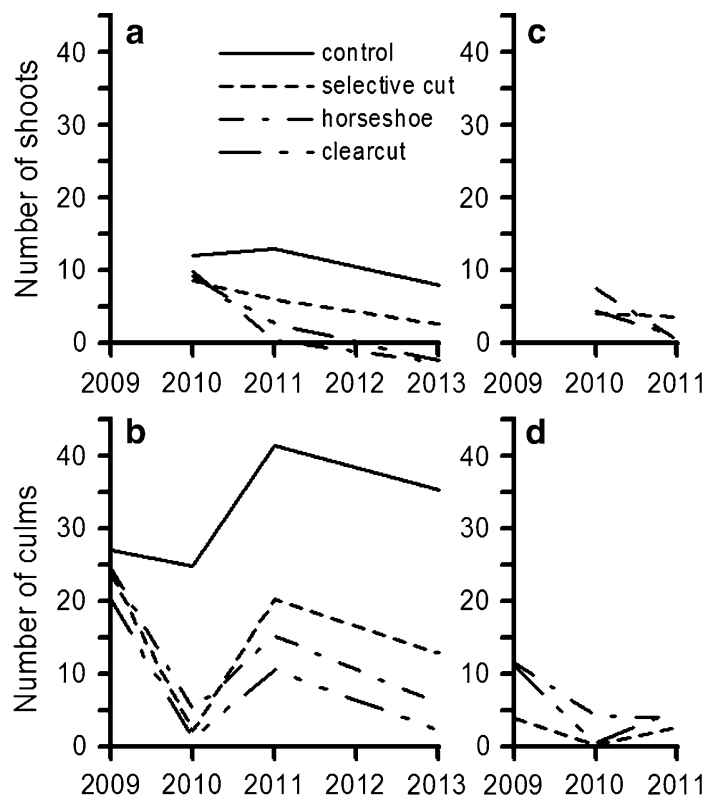

Fig. 5 Number of shoots recruited $(a)$, culms recruited $(b)$, shoots harvested $(c)$, and culms harvested $(d)$ under different treatment regimes over time

Selective cut was initially easier to implement as compared to the horseshoe cut, but subsequently its implementation was more difficult. Cutting of culms with low stumps in clump centers was difficult and frequently dangerous, despite reduced culm densities. Situations where harvested culms had to be extracted from among interlocking culms under tension were common and frequently led to damaged culms. Overall, users preferred the application of the horseshoe method.

\section{Discussion}

\section{Experimental Design Based on Users' Objectives}

LEK is believed to promote sustainable utilization of natural resources, particularly where scientific knowledge is lacking (Berkes et al. 2000). In our case, local users had rich LEK on growth conditions and other aspects necessary

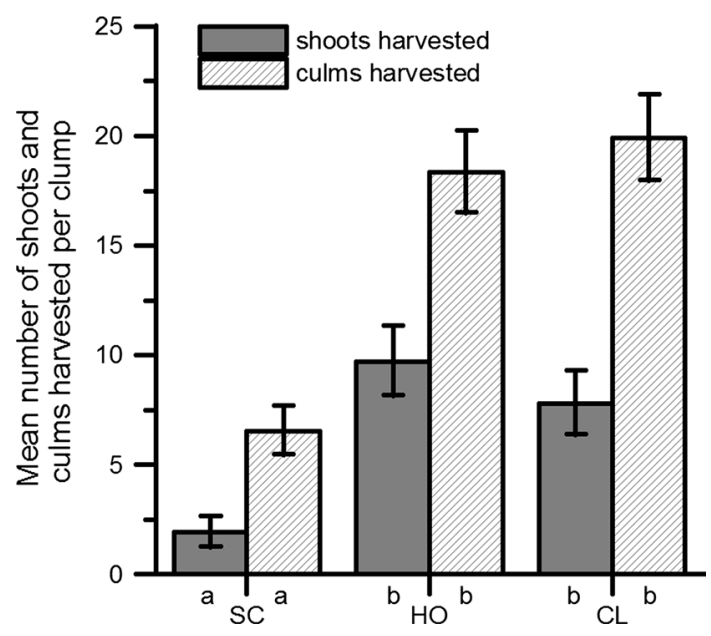

Fig. 6 Total number of shoots and culms harvested per Dendrocalamus hamiltonii clump under different harvest regimes (estimated marginal mean $\pm \mathrm{SE}$ resulting from MANCOVA; $S C$ selective cut, $H O$ horseshoe cut, $C L$ clear cut)

to implement the extensive, very low intensity harvesting, which was the traditional resource management system for D. hamiltonii. At the same time, they lacked knowledge on more intensive harvest of the species, which aims at producing more diverse products, reflecting changing local socio-economic priorities. This study tapped into LEK of forest users to design more intensive harvest methods. Local users were interested in extensive clump management practices leading to the simultaneous maximization of harvestable number of shoots and culms, which has also been confirmed by other studies in the same locality (Trinh Thang et al. 2011). Due to financial and labor implications, we thus had to rule out irrigation and fertilization as possible treatments in the trial. The lack of markets has also been identified independently as the reason for low interest of local users to devote more resources towards bamboo management (Trinh Thang et al. 2011).

In this study, we included three different harvest treatments and a non-harvest control for comparison. The simultaneous interest in shoot and clump production helped define two intermediate intensity treatments, and clear cut was included as the most intensive harvest treatment.

Table 4 MANCOVA Type III test of fixed effects for Dendrocalamus hamiltonii shoots harvested per clump, and culms harvested per clump as dependent variables

\begin{tabular}{|c|c|c|c|c|c|c|}
\hline Response variable & Source & $\mathrm{DF}$ & Type III SS & Mean square & $F$ value & $\overline{\operatorname{Pr}>F}$ \\
\hline \multirow[t]{2}{*}{ Shoots harvested per clump } & Treatment & 2 & 171.40 & 85.70 & 9.59 & 0.0075 \\
\hline & Number of culms 2009 & 1 & 186.78 & 186.78 & 20.91 & 0.0018 \\
\hline \multirow[t]{2}{*}{ Culms harvested per clump } & Treatment & 2 & 304.63 & 152.31 & 23.41 & 0.0005 \\
\hline & Number of culms 2009 & 1 & 247.44 & 247.44 & 38.03 & 0.0003 \\
\hline
\end{tabular}

Bold values indicate significant interactive effects, or in their absence significant individual effects 
Cleaning of dead culms and stumps was included in all harvest treatments to reduce clump congestion and to ease harvest as stated by local users. The selective cut treatment was designed as a low-input thinning without spatial regulation of culms to be removed. The horseshoe cut method (Tewari 1992; Bradshaw 1997) was included as a more labor-intensive alternative, requiring skills in proper spatial arrangement of culms to be removed. We expected that shoots located closer to the edge of clumps were less likely to survive (Franklin 2008), in which case the horseshoe method would have provided low recruitment and yield of shoots and culms. Bamboo shoots have been reported to be heavily browsed by wild animals and destroyed by insects (Taylor and Zisheng 1987), and this was also observed with D. hamiltonii in our study site (Trinh Thang and Dorji 2010). The clear cut method was an alternative, which can be most easily and safely implemented in unmanaged, congested clumps of $D$. hamiltonii; where clumps are unmanaged, most culms are interlocking and under tension, which leads to dangerous situations during harvesting. Maintenance of a balanced age distribution with removal of older culms is generally deemed beneficial for clump vigor (Malab et al. 2009; Nath and Das 2011), but our study design did not allow for testing the effects of different age distributions on productivity.

According to the objectives defined by local users, we applied harvest treatments annually. The rationale for winter harvest of culms is scientifically proven, as the starch content of culms at this time is very low, making them unattractive to insects (Dransfied and Widjaja 1995). Local users preferred the horseshoe harvest method based on the yields of desired products and practical considerations of ease and safety of harvesting. Nevertheless, our results clearly indicated that annual harvest according to any of the applied methods was not sustainable. With the more intense methods of horseshoe cut and clear cut, shoot recruitment declined to negligible levels. Selective cut on the other hand maintained relatively stable culm populations and 4 years after the start of harvest still showed considerable recruitment of new shoots. Considering the combined output in terms of shoots and culms, this last method, however, produced significantly lower amounts as compared to the previous two. Investigation on the management of $D$. strictus, which is a close relative of $D$. hamiltonii, revealed that sustainable harvest depends on felling intensity, cutting methods, and felling cycle. Recommendations include a 3- to 4-year felling cycle with retention of new culms along with a certain number of old culms (Tewari 1992). In our case, continued annual removal of shoots and culms did not leave sufficient time for bamboo clumps to regenerate, necessitating further studies to investigate appropriate cutting cycles.

\section{Characteristics of Clump Regeneration}

The PI indicates the rate of vegetative regeneration of the bamboo clump. Other studies on harvesting large, clumpforming bamboos report a close correlation between the number of culms (Vázquez-López et al. 2004)—specifically the number of current-year culms (Malab et al. 2009) - and shoot production (PI). Even though we found indication for the above relationships to possibly hold true for $D$. hamiltonii, the number of culms harvested more closely influenced the number of shoots recruited in the following season (harvesting response). Although successful recruitment of shoots to culms may be limited (Franklin 2008), this relationship can be explained by the compensatory growth mechanism (McNaughton 1983), according to which bamboos compensate harvesting losses with increased growth of new shoots. Reduced inter-culm competition also promotes the regeneration of new shoots (Nath et al. 2006), possibly explaining why our PI initially increased with increasing intensity of the harvesting treatment. While belowground reserves stored in bamboo rhizomes are substantial, they are nevertheless a minor contributor to aboveground growth, which is mainly driven by photosynthesis of one-year leaves ( $\mathrm{Li}$ et al. 1998). As a result, our treatments defined by a greater intensity of shoot harvest led to a greater decline in the recruitment of new shoots. At a nearby study on intensive management of $D$. hamiltonii clumps for bamboo shoot production, Trinh Thang and Dorji (2010) found comparable numbers of culms per clump and proportions of shoots $(\mathrm{PI}=0.17)$ in untreated clumps, as reported in the present study for untreated clumps $(0.2)$.

\section{Shoot and Culm Recruitment and Harvesting Under Different Treatments}

Annual application of harvest treatments exceeded the level of self-replacement, as indicated by the decline in shoot recruitment, and this needs to be considered when designing cutting cycles. Apparently, the harvest simulated with our experimental treatments was not sustainable. In spite of the continuous application of different levels of shoot removal, we did not find significant differences in total shoot recruitment between treatments, due to compensatory growth (Vázquez-López et al. 2004; Decipulo et al. 2009). We did not find evidence for clump congestion restricting shoot recruitment (Decipulo et al. 2009; Malab et al. 2009), as shoot recruitment was highest in the control treatment throughout the study.

The high combined harvested output in shoots and culms with the horseshoe cut was likely a result of increased edge length of clumps and decreased distance of culms from the clump edges. Horseshoe cut avoids 
congestion of clumps, and leads to improved clump vigor, manifested through increased shoot recruitment (Malab et al. 2009; Franklin 2008). The high combined harvest output in the clear cut treatment is likely a result of compensatory growth response to virtually complete removal of photosynthesizing biomass (McNaughton 1983). While a trade-off between shoot and culm production was observed with $D$. asper (Decipulo et al. 2009), this was not observed in our case.

\section{Conclusions}

Before markets are readily available for bamboo products, local users have low willingness to invest into management of Dendrocalamus hamiltonii. The notable exceptions are silvicultural interventions, resulting in the harvest of shoots and culms, both for domestic consumption and for limited sale. Local ecological knowledge alone may not provide answers to the sustainable utilization of NTFPs under previously unprecedented, more intensive management. As a result, we developed and tested silvicultural methods in a participatory action research framework integrating local ecological knowledge. Tested silvicultural methods lead to high yield of shoots and culms in the first years of harvesting. Weaker intensity selective cut appeared to be sustainable until the third year of consecutive harvesting, while higher intensity horseshoe cut and clear cut yielded more shoots and culms. However, annual harvest over several years jeopardizes clump productivity. The horseshoe cut method was easy to administer after initially greater investment of labor and maximized safety of work while harvesting. The study highlighted the need to follow harvesting experiments for a number of years to avoid drawing early conclusions and the need to conduct research on longer cutting cycles.

Acknowledgments We would like to thank Sangay and Georg Gratzer for technical support throughout the work. We are also grateful to Nar B. Tamang and Jigme Wangchuk for administrative support. Pankey Dukpa, Sonam Tobgay, and Dorji Dukpa helped us with setting up links to the local community and identifying research objectives. The research was funded by the Royal Government of Bhutan and the Government of Austria through the Forest Research for Development Partnership.

\section{Compliance with Ethical Standards}

Conflict of Interest The authors declare that they have no conflict of interest.

Open Access This article is distributed under the terms of the Creative Commons Attribution 4.0 International License (http://crea tivecommons.org/licenses/by/4.0/), which permits unrestricted use, distribution, and reproduction in any medium, provided you give appropriate credit to the original author(s) and the source, provide a link to the Creative Commons license, and indicate if changes were made.

\section{References}

Angelsen A, Wunder S (2003) Exploring the forest-poverty link: key concepts, issues and research implications. CIFOR Occasional Paper 40. CIFOR, Bogor

Arnold JM, Pérez AM (2001) Can non-timber forest products match tropical forest conservation and development objectives? Ecol Econ 39(3):437-447

Ballard H, Huntsinger L (2006) Salal harvester local ecological knowledge, harvest practices and understory management on the Olympic Peninsula, Washington. Hum Ecol 34:529-547

Belcher B, Ruíz-Pérez M, Achdiawan R (2005) Global patterns and trends in the use and management of commercial NTFPs: implications for livelihoods and conservation. World Dev 33:1435-1452

Belcher B, Schreckenberg K (2007) Commercialisation of non-timber forest products: a reality check. Dev Policy Rev 25:355-377

Berkes F, Colding J, Folke C (2000) Rediscovery of traditional ecological knowledge as adaptive management. Ecol App 10:1251-1262

Bhatt BP, Singha LB, Singh K, Sachan MS (2003) Commercial edible bamboo species and their market potentiality in three Indian tribal states of the North Eastern Himalayan Region. J Bamboo Rattan 2:111-133

Bhatt BP, Singh K, Singh A (2005) Nutritional values of some commercial edible bamboo species of the North Eastern Himalayan region, India. J Bamboo Rattan 4:111-124

Bradshaw RI (1997) Bamboo in Nepal: a management guide

Chalmers N, Fabricius C (2007) Expert and generalist local knowledge about land-cover change on South Africa's Wild Coast: can local ecological knowledge add value to science? Ecol Soc 12:10

Decipulo MS, Ockerby SE, Midmore DJ (2009) Managing clumps of Dendrocalamus asper in Bukidnon, the Philippines. In: Midmore DJ (ed) Silvicultural management of bamboo in the Philippines and Australia for shoots and timber. ACIAR, Canberra, pp 36-45

Dransfied S, Widjaja EA (eds) (1995) Plant resources of South-east Asia No.7 Bamboos. Backhuys Publishers, Leiden

Franklin DC (2008) Fate of culm shoots in wild stands of a tropical clumping bamboo. J Sustain For 26:97-111

Gross National Happiness Commission (2008) Tenth Five Year Plan (2008-2013). Royal Government of Bhutan, Thimphu

Huntington HP (2000) Using traditional ecological knowledge in science: methods and applications. Ecol Appl 10(5):1270-1274

Ingram J (2008) Are farmers in England equipped to meet the knowledge challenge of sustainable soil management? An analysis of farmer and advisor views. J Environ Manag $86: 214-228$

Kainer KA, DiGiano ML, Duchelle AE, Wadt LHO, Bruna E, Dain JL (2009) Partnering for greater success: local stakeholders and research in tropical biology and conservation. Biotropica 41:555-562

Kenward M, Roger J (1997) Small sample inference for fixed effects from restricted maximum likelihood. Biometrics 53:983-997

Kleinhenz V, Midmore DJ (2001) Aspects of bamboo agronomy. Adv Agron 74:99-145

Krishnankutty CN (2004) Benefit-cost analysis of bamboo in comparison with other crops in mixed cropping home gardens in Kerala State, India. J Bamboo Rattan 3:99-106

Kristjanson P, Reid RS, Dickson N, Clark WC, Romney D, Puskur R, MacMillan S, Grace D (2009) Linking international agricultural 
research knowledge with action for sustainable development. PNAS 106:5047-5052

Kusters K, Achdiawan R, Belcher B, Pérez MR (2006) Balancing development and conservation? An assessment of livelihood and environmental outcomes of nontimber forest product trade in Asia, Africa, and Latin America. Ecol Soc 11:22

Leach M, Mearns R, Scoones I (1999) Environmental entitlements: dynamics and institutions in community-based natural resource management. World Dev 27:225-247

Li R, Werger M, During H, Zhong Z (1998) Carbon and nutrient dynamics in relation to growth rhythm in the giant bamboo Phyllostachys pubescens. Plant Soil 201:113-123

Lobovikov M, Schoene D, Yping L (2012) Bamboo in climate change and rural livelihoods. Mitig Adapt Strateg Glob Change $17: 261-276$

Malab SC, Batin CB, Malab BS, Alipon MA, Midmore DJ (2009) Improving productivity of a previously unmanaged Bambusa blumeana plantation for culms and shoots in Ilocos Norte, the Philippines. In: Midmore DJ (ed) Silvicultural management of bamboo in the Philippines and Australia for shoots and timber. ACIAR, Canberra, pp 24-53

Marquez CB (2009) Improving and maintaining productivity of Bambusa blumeana for quality shoots and timber Iloilo and Capiz, the Philippines. In: Midmore DJ (ed) Silvicultural management of bamboo in the Philippines and Australia for shoots and timber. ACIAR, Canberra, pp 46-60

Marshall E, Newton A, Schreckenberg K (2003) Commercialisation of non-timber forest products: first steps in analysing the factors influencing success. Int For Rev 5:128-137

McNaughton SJ (1983) Compensatory plant growth as a response to herbivory. Oikos 40:329-336

Midmore DJ (ed) (2009) Silvicultural management of bamboo in the Philippines and Australia for shoots and timber. ACIAR, Canberra

Moktan MR, Norbu L, Dukpa K, Rai TB, Dorji R, Dhendup K, Gyeltshen N (2009) Bamboo and cane vulnerability and income generation in the rural household subsistence of Bjoka, Zhemgang, Bhutan. Mt Res Dev 29:230-240

Nath AJ, Das AK (2011) Population status and regeneration of a tropical clumping bamboo Schizostachyum dullooa under two management regimes. J For Res 22:43-46

Nath AJ, Das G, Das AK (2006) Population structure and culm production of bamboos under traditional harvest regimes in Assam, Northeast India. J Bamboo Rattan 5:79-88

Nath AJ, Lal R, Das AK (2015a) Ethnopedology and soil properties in bamboo (Bambusa sp.) based agroforestry system in North East India. Catena 135:92-99

Nath AJ, Lal R, Das AK (2015b) Managing woody bamboos for carbon farming and carbon trading. Glob Ecol Conserv 3:654-663

Pandit BH, Kumar C (2010) Factors influencing the integration of non-timber forest products into field crop cultivation: a case study from eastern Nepal. J Sustain For 29:671-695

Prommegger W, Budur K, Dorji Chhetri PB (2005) Lemon grass distillation in eastern Bhutan-a scenario analysis. RNR-RC Jakar, Bumthang

Rao KS, Saxena KS (1995) Effect of land use on Dendrocalamus hamiltonii regeneration during early secondary successional stages in northeast India. J Trop For Sci 7:347-354

Rist L, Shaanker RU, Milner-Gulland EJ, Ghazoul J (2010) The use of traditional ecological knowledge in forest management: an example from India. Ecol Soc 15:3
SAS Institute Inc. (2002-2008) SAS 9.2. SAS Institute Inc., Cary

Scheiner SM (2001) MANOVA. In: Scheiner SM, Gurevitch J (eds) Design and Analysis of Ecological Experiments. Oxford University Press, New York, pp 99-115

Seethalakshmi KK, Kumar MSM (1998) Bamboos of India. Kerala Forest Research Institute, Peechi

Social Forestry Division (2008) National strategy for the development of non-wood forest products 2008-2018. Ministry of Agriculture, Thimphu

Sprugel DG (1983) Correcting for bias in log-transformed allometric equations. Ecology 64:209-210

Stapleton CMA (2000) Bambusae. In: Noltie HJ (ed) The grasses of Bhutan, flora of Bhutan. Royal Botanic Garden, Edinburgh, pp 482-515

Stapleton CMA, Barrow S, Pradhan R (1997) Bamboo and cane study of Zhemgang Dzongkhag. Ministry of Agriculture, Thimphu

Sunderlin WD, Dewi S, Puntodewo A, Müller D, Angelsen A, Epprecht M (2008) Why forests are important for global poverty alleviation: a spatial explanation. Ecol Soc 13:24

Sundriyal M, Sundriyal RC (2004) Wild edible plants of the Sikkim Himalaya: marketing, value addition and implications for management. Econ Bot 58:300-315

Taylor AH, Zisheng Q (1987) Culm dynamics and dry matter production of bamboos in the Wolong and Tangjiahe Giant Panda Reserves, Sichuan, China. J Appl Ecol 24:419-433

Tewari DN (1992) Silviculture and management of bamboos in India. In: Tewari DN (ed) A monograph on bamboo. International Book Distributors, Dehra Dun, pp 169-186

Ticktin T, Johns T (2002) Chinanteco management of Aechmea Magdalenae: implications for the use of TEK and TRM in management plans. Econ Bot 56:177-191

Ticktin T, Nantel P, Ramirez F, Johns T (2002) Effects of variation on harvest limits for nontimber forest species in Mexico. Conserv Biol 16:691-705

Trinh Thang L, Dorji T (2010) Bamboo for shoot production: identifying the best management options using an action learning approach. Social Forestry Division, Department of Forests

Trinh Thang L, Samten W, Dendup T (2011) Report on evaluation of action learning research site, bamboo management training and bamboo shoot enterprise development feasibility study in Zhemgang. Social Forestry Division, Department of Forests

Troup RS (1921) The silviculture of Indian trees III. Oxford University Press, Oxford

Vázquez-López JM, Vibrans H, García-Moya E, Valdez-Hernández JI, Romero-Manzanares A, Cuevas-Guzmán R (2004) Effects of harvesting on the structure of a neotropical woody bamboo (Otatea: Guaduinae) populations. Interciencia 29:207-211

Virtucio FD (2009) General overview of bamboo in the Philippines. In: Midmore DJ (ed) Silvicultural management of bamboo in the Philippines and Australia for shoots and timber. ACIAR, Canberra, pp 18-23

Winer BJ (1971) Statistical principles in experimental design, 2nd edn. McGraw-Hill, New York

Wong JLG, Thornber K, Baker N (2001) Resource assessment of nonwood forest products-experience and biometric principles. FAO NWFP Series 13, Rome

Zhu Z (2003) The industrialization and market orientation of bamboo shoot production in Lin'an County: a case study. J Bamboo Rattan 2:441-452 